\title{
Presence of activating KRAS mutations correlates significantly with expression of tumour suppressor genes DCN and TPM I in colorectal cancer
}

\author{
Vid Mlakar1, Gašper Berginc ${ }^{1}$, Metka Volavšek ${ }^{1}$, Zdravko Štor ${ }^{2}$, Miran Rems ${ }^{3}$ \\ and Damjan Glavač*1
}

Address: ${ }^{1}$ Department of Molecular Genetics, Institute of Pathology, Faculty of Medicine, University of Ljubljana, Ljubljana, Slovenia, ${ }^{2}$ Department of Abdominal Surgery, University Medical Centre Ljubljana, Ljubljana, Slovenia and ${ }^{3}$ Department of Surgery, Jesenice Hospital, Jesenice, Slovenia

Email: Vid Mlakar - vid.mlakar@mf.uni-lj.si; Gašper Berginc - gasper.berginc@mf.uni-lj.si; Metka Volavšek - metka.volavsek@mf.uni-lj.si; Zdravko Štor - zdravko.stor@mf.uni-lj.si; Miran Rems - miran.rems@sb-je.si; Damjan Glavač* - damjan.glavac@mf.uni-lj.si

* Corresponding author

Published: 13 August 2009

BMC Cancer 2009, 9:282 doi:10.1 186/147|-2407-9-282
Received: 3 February 2009

Accepted: 13 August 2009

This article is available from: http://www.biomedcentral.com/I47I-2407/9/282

(C) 2009 Mlakar et al; licensee BioMed Central Ltd.

This is an Open Access article distributed under the terms of the Creative Commons Attribution License (http://creativecommons.org/licenses/by/2.0), which permits unrestricted use, distribution, and reproduction in any medium, provided the original work is properly cited.

\begin{abstract}
Background: Despite identification of the major genes and pathways involved in the development of colorectal cancer (CRC), it has become obvious that several steps in these pathways might be bypassed by other as yet unknown genetic events that lead towards CRC. Therefore we wanted to improve our understanding of the genetic mechanisms of CRC development.
\end{abstract}

Methods: We used microarrays to identify novel genes involved in the development of CRC. Real time PCR was used for mRNA expression as well as to search for chromosomal abnormalities within candidate genes. The correlation between the expression obtained by real time PCR and the presence of the KRAS mutation was investigated.

Results: We detected significant previously undescribed underexpression in CRC for genes SLC26A3, TPMI and DCN, with a suggested tumour suppressor role. We also describe the correlation between TPMI and DCN expression and the presence of KRAS mutations in CRC. When searching for chromosomal abnormalities, we found deletion of the TPMI gene in one case of CRC, but no deletions of DCN and SLC26A3 were found.

Conclusion: Our study provides further evidence of decreased mRNA expression of three important tumour suppressor genes in cases of CRC, thus implicating them in the development of this type of cancer. Moreover, we found underexpression of the TPMI gene in a case of CRCs without KRAS mutations, showing that TPMI might serve as an alternative path of development of CRC. This downregulation could in some cases be mediated by deletion of the TPMI gene. On the other hand, the correlation of DCN underexpression with the presence of KRAS mutations suggests that $D C N$ expression is affected by the presence of activating KRAS mutations, lowering the amount of the important tumour suppressor protein decorin. 


\section{Background}

Colorectal cancer (CRC) is the third most common cancer in both men and women [1]. It remains one of the most frequent and deadly diseases [1] despite important advantages in treatment and diagnosis [2]. The evolution from normal colonic mucosa to adenoma with different grades of dysplasia and finally to invasive cancer is associated with a series of genetic events occurring over a long period [3]. Not surprisingly, the incidence of colorectal cancer increases with age, especially after 60 years. Two pathways have been proposed for colorectal cancer development. The microsatellite instability (MSI) pathway is caused by mutations in genes MLH1, MSH2, PMS2 and MSH6, which are part of the mismatch repair system. The chromosomal instability (CIN) pathway is associated with mutations in the APC gene or loss of $5 \mathrm{q}$ (APC) and mutations in the KRAS gene during progression of normal epithelium to early adenoma [4]. Loss of 18q (SMAD2, $S M A D 4, D C C$ ) is associated with progression from early to advanced adenoma [4]. Deletion of $17 \mathrm{p}$, which contains the $p 53$ gene, is involved in progression towards cancer [4]. However, only a minority of CRCs possess a full spectrum of these molecular abnormalities [5]. Moreover, even though major genes involved in the development of colorectal cancer have been identified, interestingly most of them have shown only limited value in clinical use [6]. Detection of germline mutations in MLH1, MSH2, PMS2, MSH6 and APC is used to identify individuals with a predisposition for developing hereditary nonpolyposis colon cancer (HNPCC) and familial adenomatous polyposis (FAP), respectively. However, only a small percentage of the population are carriers of these mutations $[7,8]$. On the other hand, somatic mutations in $p 53, A P C$ and KRAS have no real prognostic value in cases of sporadic colorectal cancer [6]. Nevertheless, some clinical use might come from mutations in KRAS. They have recently been shown to be involved in the response of CRCs to cetuximab, suggesting a better response of patients without KRAS mutations in CRCs $[9,10]$. This shows that several steps in CRC development might be bypassed by other as yet unknown genetic events that lead towards CRC. We therefore wanted to improve our understanding of the genetic mechanisms of CRC development. In turn, this might identify new potential tumour markers useful for clinical practice.

\section{Methods \\ Samples}

Sixteen samples of colorectal adenocarcinoma (CRC) and corresponding normal tissue were collected at the Department for Surgery at Jesenice hospital. Samples were stabilized in RNAlater (Ambion, USA) solution immediately after extraction. Samples were incubated at $4{ }^{\circ} \mathrm{C}$ overnight and stored at $-20^{\circ} \mathrm{C}$, according to the manufacturer's recommendations. The study was approved by the National
Medical Ethics Committee of the Republic of Slovenia. All 16 samples were evaluated by an expert pathologist at the Institute of Pathology, Faculty of Medicine, University of Ljubljana. Adjacent to samples stored in RNAlater tissue sections were obtained for histological evaluation. Only samples including within the range of $60 \%$ to $90 \%$ of invasive tumour cells were accepted for further analysis. Corresponding normal tissue samples contained no cancer cells as evaluated by pathologist. Tumour stage and nodal status were determined for each patient (Table 1).

\section{DNA extraction}

DNA from tissue stabilized in RNAlater (Ambion, USA) was isolated with a QIAgen kit (QIAgen) according to the manufacturer's instructions.

Table I: Samples, histology and presence of activating KRAS mutations

\begin{tabular}{|c|c|c|c|}
\hline Number & $\mathbf{T}$ & $\mathbf{N}$ & KRAS status \\
\hline I & 3 & 0 & $w t$ \\
\hline 2 & I & 0 & $w t$ \\
\hline 3 & 2 & 0 & $w t$ \\
\hline 4 & 4 & 2 & $w t$ \\
\hline 5 & 3 & 2 & $w t$ \\
\hline 6 & 3 & I & $12 G>S$ \\
\hline 7 & 3 & 2 & $13 G>D$ \\
\hline 8 & I & 0 & $12 G>S$ \\
\hline 9 & 3 & I & $13 G>D$ \\
\hline 10 & 4 & 0 & $13 G>D$ \\
\hline II & 3 & I & $w t$ \\
\hline 12 & 3 & I & $w t$ \\
\hline 13 & 3 & 0 & $12 G>S$ \\
\hline 14 & 3 & 0 & $12 G>S$ \\
\hline 15 & 3 & 0 & $13 G>D$ \\
\hline 16 & 3 & 0 & $w t$ \\
\hline
\end{tabular}

The table shows sample histological data and the presence of activating KRAS mutations. No activating KRAS mutations were found in corresponding normal tissue.

$\mathrm{T}=$ tumour stage, $\mathrm{N}=$ nodal status, $K R A S$ status - presence or absence of activating KRAS mutations. 


\section{RNA extraction}

RNA from tissue was isolated using TRI REAGENT ${ }^{\mathrm{TM}}$ (Sigma Aldrich) and the PureLinkTM Micro-to-Midi Total RNA Purification System (Invitrogen), according to the manufacturer's instructions. Briefly, 50 - $100 \mathrm{mg}$ of tissue was homogenized in TRI REAGENT ${ }^{\mathrm{Tm}}$ using PT 3100 homogenizer (Polytron). The homogenate was centrifuged at $12000 \times \mathrm{g}$ for $10 \mathrm{~min}$ at $4{ }^{\circ} \mathrm{C}$ to remove insoluble material and the supernatant was transferred to a fresh microcentrifuge tube. Samples were allowed to sit at room temperature for $5 \mathrm{~min}$, and $0.2 \mathrm{ml}$ of chloroform was added per $1 \mathrm{ml}$ of TRI REAGENT ${ }^{\mathrm{TM}}$. Samples were mixed by hand for $15 \mathrm{~s}$ and allowed to stand for 2 - $15 \mathrm{~min}$ at room temperature. The resulting mixture was centrifuged at $12000 \times \mathrm{g}$ for $15 \mathrm{~min}$ at $4^{\circ} \mathrm{C}$. The aqueous phase was transferred to a fresh microcentrifuge tube and an equal amount of $70 \%$ ethanol was added. Samples were transferred to a PureLinkTM Micro-to-Midi Total RNA Purification System column (Invitrogen) and processed according to the manufacturer's protocol. All samples were washed from the column with $75 \mu$ l of RNAse free water.

\section{Analysis of RNA}

The quality of RNA was checked on a Bioanalyzer 2100 (Agilent) using an RNA 6000 Nano Labchip (Agilent) and a 6000 RNA ladder as reference (Ambion). The concentration and quantity of RNA was determined with ND-1000 (Nanodrop, USA).

\section{Preparation of aaRNA}

Preparation of aaRNA was performed with an Amino Allyl MessageAmp $^{\text {тм }}$ II aRNA Amplification Kit (Ambion) according to the manufacturer's recommendations. For each hybridization, we labelled $5 \mu \mathrm{g}$ of normal (Cy3) and $5 \mu \mathrm{g}$ of tumour (Cy5) mRNA. After removing the excess dye, the RNAs were dissolved in Nexterion Hybridization solution (Schott Nexterion).

\section{Microarrays}

Microarrays were prepared with Human Apoptosis Subset v2.0 and Human Cancer Subset v3.0 (Operon) 70mer oligonucleotides and Nexterion 70mer Oligo Microarraying Kit (Schott Nexterion) slides. Oligonucleotides were spotted using an MG1000 spotter (MicroGrid), immobilised and stored according to the manufacturer's instructions (Schott Nexterion). All hybridisations were performed on HS400 (Tecan) according to the manufacturer's instructions (Schott Nexterion). We used an LS200 scanner (Tecan) at $6 \mu \mathrm{m}$ resolution for scanning the microarrays.

\section{Real time PCR}

We used Taqman Reverse transcription reagent (Applied Biosystems) for cDNA synthesis. Expression of the SLC26A3, DCN, CALM3 and TPM1 genes in tumour samples relative to their normal adjacent tissues was measured using quantitative real time PCR based on the TaqMan ${ }^{\circledR}$ fluorescence methodology. A ready mixture of probes and primers specific for SLC26A3 mRNA expression (Assayon-Demand $^{\mathrm{TM}}$, Hs00995363_m1 (Applied Biosystems)), DCN mRNA expression (Assay-on-Demand ${ }^{\mathrm{TM}}$, Hs00266491_m1 (Applied Biosystems)), CALM3 mRNA expression (Assay-on-Demand ${ }^{\mathrm{TM}}$, Hs00270914_m1 (Applied Biosystems)), TPM1 mRNA expression (Assayon-Demand $^{\mathrm{TM}}$, Hs00165966_m1 (Applied Biosystems)) and Pre-Developed TaqMan Assay Reagents Human GAPDH $(20 \times)$ mRNA (Applied Biosystems) were used as the endogenous control gene. All measurements were done in triplicate. The relative quantification of mRNA levels of the target was determined using the $\Delta \Delta \mathrm{C}_{\mathrm{T}}\left(\Delta \Delta \mathrm{C}_{\mathrm{T}}\right.$ $\left.=\Delta \mathrm{C}_{\mathrm{T} \text { normal }}-\Delta \mathrm{C}_{\mathrm{T} \text { tumour }} ; \Delta \mathrm{C}_{\mathrm{T}}=\Delta \mathrm{C}_{\mathrm{Tx}}-\Delta \mathrm{C}_{\mathrm{T} \text { GAPDH }}\right)$ method, unless stated otherwise.

\section{Copy number}

Gene copy number was determined by using real time PCR based on the TaqMan fluorescence methodology. The assays, TaqMan RNase P Detection Reagents (Applied Biosystems) and Assay-by-Design for TPM1, SLC26A3 and DCN (Applied Biosystems) gene detection were performed according to the manufacturer's instructions. Assay-by-Design for the TPM1 gene contained the following primers and probe: forward primer: GGAAAGTACATATCTGGGAGAAGCA, reverse primer: TTCTTGATG GCGTCCATGGT, probe: FAM TCGCACTCCCGCTCCT. Assay-by-Design for the SLC26A3 gene contained the following primers and probe: forward primer: GCCACAGCCAACAGAAAAATCAAAAT, reverse primer: CCTCAAAAGCATTTGTAGAATACACTGG, probe: FAM CTGGCCACAATATAC. Assay-by-Design for the DCN gene contained the following primers and probe: forward primer: CTGATGACCGCGACTTCGA, reverse primer: CGAAGATGGCATTGACAGCG, probe: FAM CCCAGTGTGCCCCTTC. The copy numbers of TPM1, SLC26A3 and $D C N$ genes were determined on the basis of the threshold cycle difference between TPM1, SLC26A3 and DCN and the RnaseP gene. For calculation of the copy number, combined_gene_copy_number_assay_macro-1.xls (Applied Biosystems) was used.

\section{KRAS mutation detection and V64L (rs/70 I8909) detection}

The first exon of the KRAS gene of each tumour sample and corresponding normal tissue was amplified with PCR as previously described by Konig and co. [11]. Screening for changes in PCR products was performed with Single Stranded Conformation Analysis (SSCA) [12,13]. Samples showing different migration shifts were chosen for sequencing. All 16 corresponding normal tissues were also sequenced for V64L (C>A, rs17018909) polymorphism of the DCN gene, which might have an effect on performance of Hs00266491_m1 Assay-on-Demand ${ }^{\mathrm{TM}}$ 
(Applied Biosystems). Sequencing was performed using BigDye Terminator Ready Reaction Mix. Sequences were purified, dissolved and analysed on an ABI PRISM 310 Genetic Analyzer according to the manufacturer's recommendations (Applied Biosystems, USA). Nucleotide sequences were compared against the published KRAS cDNA sequence (GenBank accession number NM 014588) in order to define the mutation.

\section{Data analysis}

We used ArrayPro Analyser (Media Cybernetic, USA) software for feature extraction after imaging. Acuity 4.0 (Molecular Devices, USA) was used for filtration of bad signals, Lowess normalization and microarray data analysis. We filtered out genes that were not expressed in all 16 samples and showed a median expression of 1.5 times. Results on differentially expressed genes were compared to 5 major expression studies available from the PubMed GEO project [14-18] and evidence of independent validation of gene expression data was checked using the PubMed database. All other statistical analyses were done using SPSS 16 (SPSS inc.). We used the paired t test to compare differences in the amount of TPM1, SLC26A3, DCN and CALM3 mRNA between CRC and corresponding normal tissue. The paired t test was also used to check the difference in GAPDH expression between corresponding normal tissue and tumour samples. The $t$ test was also used to compare pairs of samples with mutations in the KRAS gene to pairs of samples without these mutations. P $<0.05$ was considered statistically significant.

\section{Results}

The expression profiles of 16 primary human colorectal tumours were obtained by comparison of CRC mRNA with mRNA from their corresponding normal tissue on a 3060 element microarray from Operon. In our experimental design, microarrays were used as a dual colour system in which CRC and the corresponding normal mRNA were separately labelled, mixed and hybridised together on each array. The acquired data were analysed with Acuity 4.0 to select reliable data. Only genes present in all 16 microarrays were considered for further processing. Out of 3060 genes, 30 genes showed differential expression (see additional file 1[14-18]).

Because of the manageable number of differentially expressed genes, we crosschecked their expression to already existing microarray data (see additional file 1). Eleven out of 30 genes (SLC26A3, CASP9, VIM, LGALS4, SRI, UGP2, LGALS3, TPM1, TUBB, MAP2K7 and CRABP2) showed good concordance with multiple microarray expression studies. Ten out of 30 genes (ITGB4, CALM3, EEF1A1, HOX4A, PCDH1, KRT19, GATA2, TGFBI, RBL2, and TNA) showed variable expression between different studies. Interestingly, 3 genes (AD022, CORT, and
CARD10) were not included in any of these studies and 4 genes (DCN, NPC1, RAI1, TTYH1) were characterised in only 1 study. Only CDH12 and PMP22 showed a difference between multiple expression studies and our results. In order to enable other users comprehensively to interpret and evaluate our results, original tables of complete microarray results are available in the supplementary data (see the GEO website at http://www.ncbi.nlm.nih.gov/ projects/geo/ Series entry: GSE14010).

\section{Real time PCR}

Relative quantification real-time PCR was used to determine the difference in expression of SCL26A3, DCN, TPM1 and CALM3 between CRC and corresponding normal tissue (Figure 1). We used GAPDH as endogenous control for normalization. No statistically significant difference in expression of GAPDH between corresponding normal tissue and tumour samples was detected (paired $t$ test $p=0,113$ ). These genes were chosen because they have been shown to play a significant role in CRC development. They also showed good concordance with other microarray studies and no precise quantification of their mRNA has yet been performed.

Figure 1 shows the relative average expression of genes in comparison to normal tissue (Figure 1). In agreement with microarrays, SLC26A3, DCN, CALM3 and TPM1 showed clear downregulation. SLC26A3 was downregulated in 13 out of 16 cases (Figure 2). Two cases showed overexpression and 1 case showed almost no change in expression. SLC26A3 had 12.43 times lower expression in CRC in comparison to normal tissue ( $<<0.003)$. DCN

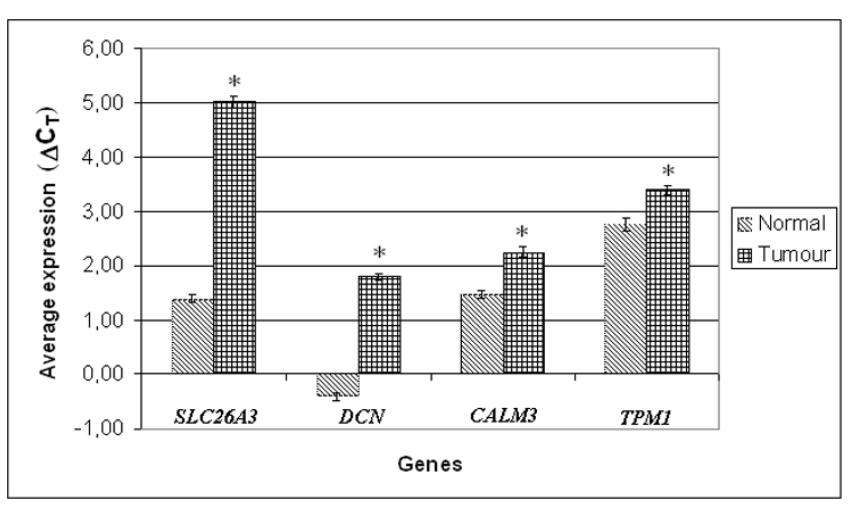

Figure I

Significant under-expression of SLC26A3, DCN, CALM3 and TPMI in tumour in comparison to normal tissue. Average expression of the SLC26A3, DCN, CALM3 and TPMI gene was significantly lower in CRC in comparison to normal tissue. Expression is shown in $\Delta \mathrm{C}_{\mathrm{T}}$ units, whereby larger $\triangle C_{T}$ value represents down-regulation of SLC26A3, DCN, CALM3 and TPMI in comparison to smaller $\Delta \mathrm{C}_{\mathrm{T}}$ of normal tissue. 


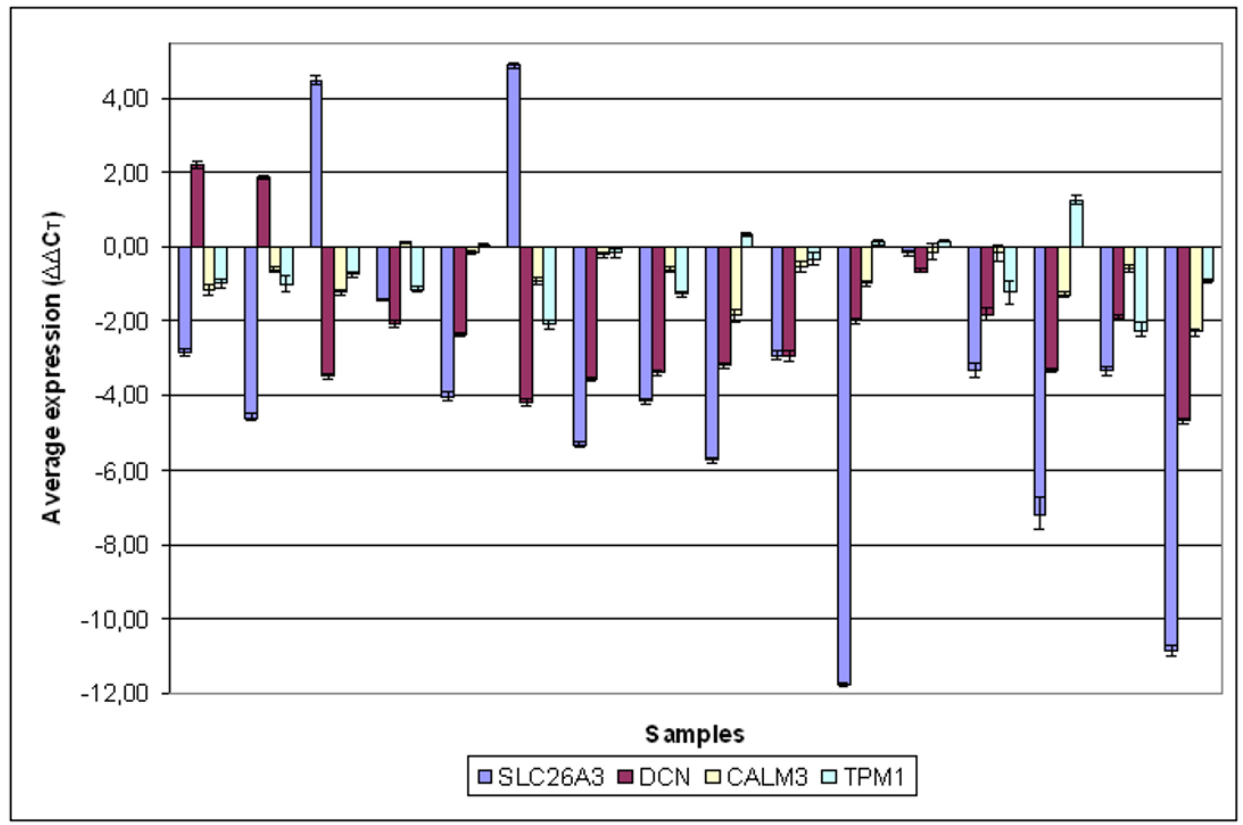

\section{Figure 2}

Expression of SLC26A3, DCN, CALM3 and TPMI in I 6 CRC in comparison to normal tissue. Expression is shown in $\Delta \Delta \mathrm{C}_{\mathrm{T}}$ units, whereby a negative $\Delta \Delta \mathrm{C}_{\mathrm{T}}$ value represents down-regulation of gene in $\mathrm{CRC}$ in comparison to corresponding normal tissue. Positive bar represents over-expression of gene in CRC in comparison to corresponding normal tissue.

was under- and overexpressed in 14 and 2 cases of CRC in comparison to normal tissue, respectively (Figure 2). CRC had on average 4.61 times less DCN than normal tissue (p $<0.007)$. We also report that we did not detect V64L polymorphism in 16 corresponding normal tissues, so no adverse effects on performance of real-time PCR was expected, as suggested by the manufacturer. CALM3 showed underexpression in 11 and no change in 5 cases of CRC (Figure 2). CRC had on average 1.7 times less CALM3 than normal tissue $(\mathrm{p}<0.003)$. TPM1 was underexpressed in 9 out of 16 cases (Figure 2 ). In only 1 case was TPM1 overexpressed in CRC in comparison to normal tissue. The remaining samples showed no major difference. TPM1 was on average 1.6 times lower in CRC that normal tissue $(\mathrm{p}<0.015)$. However, when considering only downregulated samples, 2.5 times less TPM1 mRNA was found in CRC in comparison to normal tissue.

\section{Copy number}

So far, SLC26A3, DCN and TPM1 genes have been suggested to have tumour suppressor properties. We investigated the possibility that loss of alleles could be present in the location of genes to contribute to underexpression or inactivation of the mentioned genes. We used the real time PCR method to evaluate the amount of allele present in each sample. Interestingly, although we did not find any allele loss at the site of SLC26A3 and DCN genes, we detected 1 loss of the TPM1 allele in 16 samples of CRC (data not shown).

\section{Mutation detection}

In order to detect mutations, we used the SSCA method for preliminary testing and automatic sequencing for subsequent confirmation of different patterns. We searched for mutations in codon 12 and 13, since these mutations represent 96 - 99\% of all mutations detected in CRC. Mutations in other positions, such as 66 and 146, account for around $1-4 \%$ of all mutations, although their clinical relevance in CRC is unclear [19]. We found activating mutations in codon 12 and 13 in 8 out of 16 samples (Table 1). No activating KRAS mutations were found in corresponding normal tissue. When comparing the expression difference between normal and tumour samples, we found significant underexpression of the DCN gene in the group of tumours with activating KRAS mutations in comparison with tumours without these mutations $(\mathrm{p}<0.05)$. We also found no change in expression of the TPM1 gene in CRC cases with a mutation in KRAS, in comparison with underexpression of the TPM1 gene in CRCs without activating KRAS mutations $(\mathrm{p}<0,05)$ (Figure 3).

\section{Discussion}

Major molecular pathways involved in the development of colorectal cancer have been identified [4]. However, major genes, such as $p 53$ and APC, involved in these pathways have shown only limited value in clinical use [6]. Moreover, only a minority of CRCs possess a full complement of these molecular abnormalities [5]. This shows 


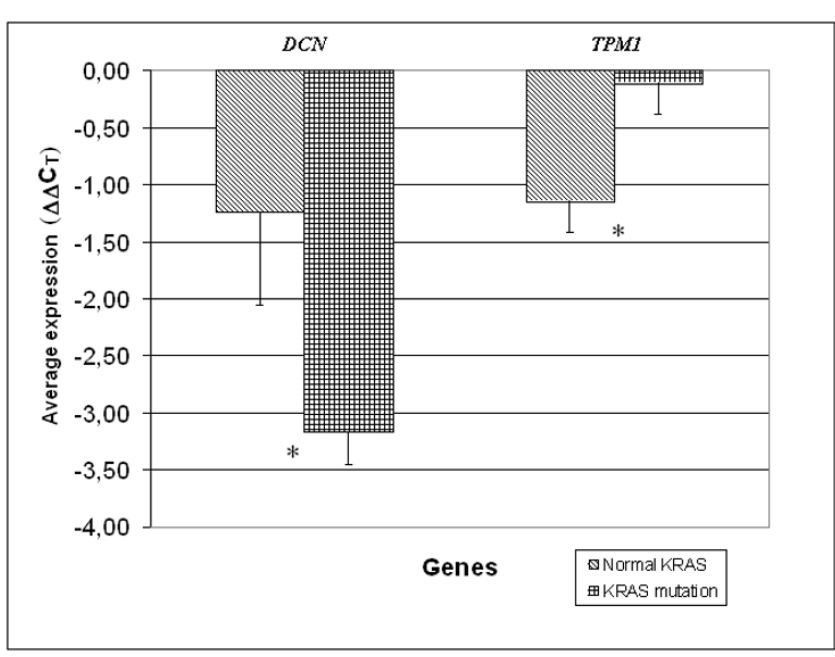

\section{Figure 3}

Expression of DCN and TPMI in pairs of samples with a different KRAS status. Expression is shown in $\Delta \Delta \mathrm{C}_{\mathrm{T}}$ units, whereby a negative $\Delta \Delta \mathrm{C}_{\mathrm{T}}$ value represents down-regulation of DCN, TPMI in comparison to normal tissue. Pairs of samples were grouped according to their KRAS status.

that several steps in CRC development might be bypassed by other as yet unknown genetic events that lead towards CRC. Using expression profiling, we set out to identify genes that may play an important role in the development of CRC, whose expression has not yet been characterized. This is also the first study performed on a cohort of Slovenian patients on this scale. We were able to identify 30 differentially expressed genes (see additional file 1). When comparing the obtained results with other studies, only 2 genes showed a large difference in expression in comparison to our study. It is noteworthy that 10 out of 30 genes showed variable expression between studies. Even more interesting was the fact that we were able to find better characterisation of expression with other methods than microarrays for only 7 of 30 genes for CRC samples (see additional file 1). These two observations show the need to characterise expression further with other, more precise methods, such as real time PCR.

In the group of genes showing good concordance with other microarray studies were SLC26A3, CASP9, VIM, LGALS4, SRI, UGP2, LGALS3, TPM1, TUBB, MAP2K7, and CRABP2. DCN and RAI1 also showed concordance with our results, although their expression was characterised in only one study. When we looked for the function of these genes, we found that three (SLC26A3, TPM1, and DCN) of them play a tumour suppressor role. Moreover, no precise expression analysis on clinical cases of CRC exists to confirm their involvement. TPM1 and DCN are also related to the KRAS signalling pathway, suggesting that their expression might change due to the presence or absence of acti- vating KRAS mutations in codon 12 and 13. Moreover, the expression of none of the three genes has so far been characterised with real time PCR in samples of CRC.

The SLC26A3 gene encodes anion transporter expressed in mucosa of the lower gastrointestinal tract [20]. Mutations in the SLC26A3 gene cause congenital chloride diarrhea (CLD) [21]. This rare condition is attributed to a lack of chlorine uptake in the colon [22]. Patients with CLD also have a higher risk of developing CRC [23]. Chapman et al also demonstrated that SLC26A3 possesses a tumour suppressor ability by inhibiting cell growth in cells transfected with functional SLC26A3. Moreover, they showed that the tumour suppressor role is separated from the role of anion transporter [24]. This suggests that SLC26A3 is not downregulated as a result of transition of normal colon mucosa towards CRC, but plays an active role in CRC development. The few studies investigating expression of SLC26A3 so far have only used subtractive hybridization and northern blot to show that SLC26A3 is downregulated in adenomas of colon. Using northern blot analysis, Anthalis et al. observed progressive downregulation of SLC26A3 from normal mucosa to polyp and finally to CRC [25]. These methods are not as precise as the real time PCR method used in this study, which provides more accurate and reproducible quantification with a larger dynamic range. In agreement with above mentioned data, we report underexpression of SLC26A3 in CRC in comparison with corresponding normal tissue. SLC26A3 mRNA was on average 12.4 times underexpressed $(p<0.01)$ in CRC than normal surrounding mucosa. Because abnormalities of chromosome 7 have been associated with colorectal carcinoma, we also hypothesised that loss of alleles might lead to underexpression of SLC26A3. However, no loss of SLC26A3 was detected using the real-time PCR methodology, showing that some other mechanism must be involved in downregulation of the SLC26A3 gene.

Decorin is a member of the small leucine-rich proteoglycan gene family. Implication of decorin in the regulation of cell cycle has been suggested by numerous studies. Overexpression of decorin in Chinese hamster ovary cells inhibits cell proliferation [26]. Santra et al. showed that de novo expression of decorin leads to an arrest of transformed cells in the G1 phase of the cell cycle. Moreover, they were able to restore growth by blocking decorin transcription via aDcns [27]. The tumour suppressor activity of decorin is mediated through various pathways. Seidler and co. showed that decorin causes a reduction of activity and decline in total EGFR in tumour cells. Moreover, the same group showed that decorin also activates caspase-3, the key enzyme in apoptosis [28]. Decorin causes the induction of $\mathrm{p} 21$, which in turn leads to growth suppression [29]. Decorin also has binding sites for TGF- $\beta$, 
through which it apparently modulates the action of this important citokine [30]. Interestingly, although many tumour suppressor effects have been associated with decorin, no precise quantification by real time PCR has been performed. However, decorin protein under-expression in CRC has been clearly established using immunohistochemistry [31]. We are the first to report and characterise decorin expression on the mRNA level using a real-time PCR quantification method. Our results show that the DCN gene is 4.6 times $(\mathrm{p}<0.01)$ underexpressed in tumour than normal tissue. However, in two CRC samples we found decorin overexpression in comparison to normal tissue. Because Decorin acts through EGFR, we speculated that we might see a difference in DCN expression between CRCs with KRAS mutations and CRCs without them. We found that CRCs with activating mutations in the KRAS gene showed much larger underexpression of the DCN gene in comparison to normal tissue than CRCs without mutations in KRAS. In the Fearon and Vogelstein model, activating KRAS mutations are one of the first genomic events leading to the development of CRC. This in turn suggests that underexpression of the DCN gene might be early consequence of acquired activating KRAS mutations [32]. Moreover, as reported previously, overexpression of decorin also plays a role in TGF- $\beta$ by inhibiting its synthesis and bioactivity, thus entering another important CRC development pathway as a tumour suppressor gene [30]. The importance of decorin downregulation for the development of CRC is further emphasized by its downregulation despite the absence of activating KRAS mutations. Lastly, we found no deletions of the $D C N$ gene using the real-time PCR method, showing that either methylation of promoter or suppression by transactivating elements must be responsible for $D C N$ underexpression in a tumour.

Tropomyosines are important actin binding proteins. The actin cytoskeleton plays an important role in regulation of cell proliferation, apoptosis, cell migration, invasion and anchorage independent growth [33]. Tropomysine 1 is consistently abolished in a number of human cancer cell lines and tissues [34,35]. Moreover, it has been demonstrated that tropomysin 1 (TPM1) has tumour suppressor properties [36] and it can revert transformed phenotype [37]. Despite the obvious importance of TPM1 in tumour development, data on TPM1 gene expression in clinical samples of CRC samples in comparison to corresponding normal tissue do not exist. Our data obtained by real-time PCR show 1.6 times lower expression of TPM1 in CRCs, which supports the current view of TPM1 as a tumour suppressor. TPM1 was underexpressed in 9 out of 16 cases, in 6 samples no major difference between CRC and normal tissue was found and in 1 case we found TPM1 overexpression. More interesting was the observation that TPM1 was much more underexpressed in CRCs not harbouring
KRAS mutations in comparison to normal tissue. In CRCs with a KRAS mutation, we found almost no difference in expression to normal tissue. This observation suggests the conclusion that downregulation of TPM1 is independent of the constitutively activated KRAS pathway. This is also in agreement with the observation that epigenetic factors such as methylation of the promoter region cause TPM1 downregulation. Moreover, we also report identification of TPM1 gene loss in $1 \mathrm{CRC}$, showing that loss of genetic material could also be responsible for underexpression of the TPM1 gene. This is in agreement with the hypothesis that epigenetic and genetic events are responsible for TPM1 downregulation, rather than inhibition by trans acting elements.

One of the interesting results from microarrays was underexpression of the CALM3 gene, which codes for calmodulin protein. Since expression of calmodulin 3 was variable among different microarray studies (see additional file 1) we validated our result with real-time PCR and confirmed the observed underexpression of CALM3 in CRC. However, this result is in contrast with its proposed cell cycle promotion role, which is reflected by the arrest of the mitotic cycle by anti-CaM drugs added to a wide variety of cells [38]. Moreover, addition of monoclonal antibody against CaM inhibited DNA synthesis and progression through G1, and mitosis exit was sensitive to intracellular concentrations of CaM [39]. Calmodulin in higher vertebrates is encoded by three genes, although all three genes code for an identical calmodulin protein consisting of 148 amino acids [40]. This raises the question of whether the other two CALM genes are expressed in a different way. Surprisingly, both CALM1 and CALM2 showed significant underexpression, as reported by various microarray studies [14-17]. This observation supports the hypothesis proposed by Kahl and Means that cancer cells containing a disruption in the cyclin $\mathrm{D} / \mathrm{cdk} 47 \mathrm{pRb}$ regulatory pathway, may no longer require $\mathrm{Ca} 2+/ \mathrm{CaM}$ to regulate the activation of this pathway because it is already activated or unnecessary for G1 progression in the tumour cells [38]. One other possible explanation of such a result is that the position in the cell rather than the amount of calmodulin is enough to promote cell cycle. The cell could achieve this positioning of calmodulin by targeting CALM mRNAs to a different intracellular compartment $[41,42]$.

\section{Conclusion}

In conclusion, we detected significant under-expression of genes SLC26A3, TPM1, DCN and CALM3 in CRC, providing further evidence of their decreased mRNA expression and thus implicating them in the development of this type of cancer. We also described a correlation between TPM1 and DCN expression and the presence of KRAS mutations in CRC. When searching for chromosomal abnormalities, we found deletion of the TPM1 gene in one case of CRC, 
and no deletions of DCN and SLC26A3 were found. Moreover, we found underexpression of the TPM1 gene in cases of CRCs without KRAS mutations, showing that TPM1 might serve as an alternative path of development of CRC. This downregulation could in some cases be mediated by deletion of the TPM1 gene. On the other hand, the correlation of DCN underexpression with the presence of KRAS mutations, suggests that $D C N$ expression is affected by the presence of activating KRAS mutations, lowering the amount of the important tumour suppressor protein decorin.

\section{Competing interests}

The authors declare that they have no competing interests.

\section{Authors' contributions}

VM carried out the analysis of KRAS mutations, real-time PCR and wrote and prepared the manuscript. VM and GB carried out microarray and statistical analysis and participated in the design of the study. ZŠ and MR did the surgery and obtained samples and informed consents from patients. MV helped with pathological evaluation of tissue samples and histological staging. DG conceived the study, and participated in its design and coordination and helped to draft the manuscript. All authors read and approved the final manuscript.

\section{Additional material}

\section{Additional file 1}

Table 2 Differentially expressed genes in 16 colorectal cancers in direct comparison to corresponding normal tissue. The column, Independent validation, contains the result of a search for articles describing particular gene expression on the level of mRNA in CRC, done with methods other than microarray. References 14-18 were used to compare gene expression.

Click here for file

[http://www.biomedcentral.com/content/supplementary/14712407-9-282-S1.doc]

\section{Acknowledgements}

This work was supported by the Slovenian Research Agency (ARRS) (Program P3-054). This work is a part of the PhD thesis of candidate Vid Mlakar, BSc of Microbiology.

\section{References}

I. Jemal A, Murray T, Ward E, Samuels A, Tiwari RC, Ghafoor A, Feuer EJ, Thun MJ: Cancer statistics, 2005. CA Cancer J Clin 2005, 55:10-30.

2. Goldberg RM, Gill S: Recent phase III trials of fluorouracil, irinotecan, and oxaliplatin as chemotherapy for metastatic colorectal cancer. Cancer Chemother Pharmacol 2004, 54(Suppl I):S57-64.

3. Worthley DL, Whitehall VL, Spring KJ, Leggett BA: Colorectal carcinogenesis: Road maps to cancer. World J Gastroenterol 2007, | 3:3784-379|.

4. Grady WM: Genomic instability and colon cancer. Cancer Metastasis Rev 2004, 23: I I-27.
5. Smith G, Carey FA, Beattie J, Wilkie MJ, Lightfoot TJ, Coxhead J, Garner RC, Steele RJ, Wolf CR: Mutations in APC, Kirsten-ras, and p53 - alternative genetic pathways to colorectal cancer. Proc Natl Acad Sci USA 2002, 99:9433-9438.

6. Conlin A, Smith G, Carey FA, Wolf CR, Steele RJ: The prognostic significance of K-ras, p53, and APC mutations in colorectal carcinoma. Gut 2005, 54:1283-1286.

7. Fearnhead NS, Britton MP, Bodmer WF: The ABC of APC. Hum Mol Genet 200I, I 0:72I-733.

8. Lynch HT, Smyrk T, Lynch JF: Overview of natural history, pathology, molecular genetics and management of HNPCC (Lynch Syndrome). Int ] Cancer 1996, 69:38-43.

9. Lievere A, Bachet J-B, Corre DL, Boige V, Landi B, Emile J-F, Cote J$F$, Tomasic G, Penna C, Ducreux M, Rougier P, Penault-Llorca F, Laurent-Puig P: KRAS mutation status is predictive of response to cetuximab therapy in colorectal cancer. Cancer Res 2006, 66:3992-3995.

10. Di Fiore F, Blanchard F, Charbonnier F, Le Pessot F, Lamy A, Galais MP, Bastit L, Killian A, Sesboüé R, Tuech JJ, Queuniet AM, Paillot B, Sabourin JC, Michot F, Michel P, Frebourg T: Clinical relevance of KRAS mutation detection in metastatic colorectal cancer treated by Cetuximab plus chemotherapy. Br J Cancer 2007, 96: I166-1169.

II. König EA, Köves I, Raşinariu A, Popp AR, Kusser WC, Soyonki K, Kovács A, Glickman BW, Jeney A, Marcsek ZL: Alterations of K-ras and p53 mutations in colorectal cancer patients in Central Europe. J Toxicol Environ Health A 200I, 62:333-347.

12. Ravnik-Glavac M, Glavac D, Dean M: Sensitivity of single-strand conformation polymorphism and heteroduplex method for mutation detection in the cystic fibrosis gene. Hum Mol Genet 1994, 3:80I-807.

13. Glavac D, Dean M: Optimization of the single-strand conformation polymorphism (SSCP) technique for detection of point mutations. Hum Mutat 1993, 2:404-4I4.

14. Ki DH, Jeung HC, Park CH, Kang SH, Lee GY, Lee WS, Kim NK, Chung HC, Rha SY: Whole genome analysis for liver metastasis gene signatures in colorectal cancer. Int J Cancer 2007, 121:2005-2012

15. Alon U, Barkai N, Notterman DA, Gish K, Ybarra S, Mack D, Levine AJ: Broad patterns of gene expression revealed by clustering analysis of tumor and normal colon tissues probed by oligonucleotide arrays. Proc Natl Acad Sci USA 1999, 96:6745-6750.

16. Notterman DA, Alon U, Sierk AJ, Levine AJ: Transcriptional gene expression profiles of colorectal adenoma, adenocarcinoma, and normal tissue examined by oligonucleotide arrays. Cancer Res 200I, 6I:3 I24-3I30.

17. Graudens E, Boulanger V, Mollard C, Mariage-Samson R, Barlet X, Grémy G, Couillault C, Lajémi M, Piatier-Tonneau D, Zaborski P, Eveno E, Auffray C, Imbeaud S: Deciphering cellular states of innate tumor drug responses. Genome Biol 2006, 7:RI9.

18. Zou TT, Selaru FM, Xu Y, Shustova V, Yin J, Mori Y, Shibata D, Sato F, Wang S, Olaru A, Deacu E, Liu TC, Abraham JM, Meltzer SJ: Application of cDNA microarrays to generate a molecular taxonomy capable of distinguishing between colon cancer and normal colon. Oncogene 2002, 21 :4855-4862.

19. van Krieken JHJM, Jung A, Kirchner T, Carneiro F, Seruca R, Bosman FT, Quirke P, Fléjou JF, Plato Hansen T, de Hertogh G, Jares P, Langner C, Hoefler G, Ligtenberg M, Tiniakos D, Tejpar S, Bevilacqua G, Ensari A: KRAS mutation testing for predicting response to anti-EGFR therapy for colorectal carcinoma: proposal for an European quality assurance program. Virchows Arch 2008, 453:417-431.

20. Schweinfest CW, Henderson KW, Suster S, Kondoh N, Papas TS: Identification of a colon mucosa gene that is down-regulated in colon adenomas and adenocarcinomas. Proc Natl Acad Sci USA 1993, 90:4166-4I70.

21. Höglund P, Haila S, Socha J, Tomaszewski L, Saarialho-Kere U, Karjalainen-Lindsberg ML, Airola K, Holmberg C, de la Chapelle A, Kere $\mathrm{j}$ : Mutations of the Down-regulated in adenoma (DRA) gene cause congenital chloride diarrhoea. Nat Genet 1996, 14:316-319.

22. Kere J, Lohi H, Höglund P: Genetic Disorders of Membrane Transport III. Congenital chloride diarrhea. Am J Physiol I999, 276:G7-GI3.

23. Hemminki A, Höglund $P$, Pukkala E, Salovaara R, Järvinen $H$, Norio R, Aaltonen LA: Intestinal cancer in patients with a germline 
mutation in the down-regulated in adenoma (DRA) gene. Oncogene 1998, 16:681-684.

24. Chapman JM, Knoepp SM, Byeon MK, Henderson KW, Schweinfest $\mathrm{CW}$ : The colon anion transporter, down-regulated in adenoma, induces growth suppression that is abrogated by EIA. Cancer Res 2002, 62:5083-5088.

25. Antalis TM, Reeder JA, Gotley DC, Byeon MK, Walsh MD, Henderson KW, Papas TS, Schweinfest CW: Down-regulation of the down-regulated in adenoma (DRA) gene correlates with colon tumor progression. Clin Cancer Res 1998, 4:1857-I863.

26. Yamaguchi $Y$, Ruoslahti E: Expression of human proteoglycan in Chinese hamster ovary cells inhibits cell proliferation. Nature 1988, 336:244-246.

27. Santra M, Skorski T, Calabretta B, Lattime EC, lozzo RV: De novo decorin gene expression suppresses the malignant phenotype in human colon cancer cells. Proc Natl Acad Sci USA 1995, 92:7016-7020.

28. Seidler DG, Goldoni S, Agnew C, Cardi C, Thakur ML, Owens RT, McQuillan DJ, lozzo RV: Decorin protein core inhibits in vivo cancer growth and metabolism by hindering epidermal growth factor receptor function and triggering apoptosis via caspase-3 activation. J Biol Chem 2006, 281:26408-264l8.

29. De Luca A, Santra M, Baldi A, Giordano A, lozzo RV: Decorininduced growth suppression is associated with up-regulation of p2I, an inhibitor of cyclin-dependent kinases. J Biol Chem | 996, 27|: |896|-|8965.

30. Ständer $M$, Naumann $U$, Wick W, Weller M: Transforming growth factor-beta and p-2I: multiple molecular targets of decorinmediated suppression of neoplastic growth. Cell Tissue Res 1999, 296:22I-227.

31. Augoff K, Rabczynski J, Tabola R, Czapla L, Ratajczak K, Grabowski K: Immunohistochemical study of decorin expression in polyps and carcinomas of the colon. Med Sci Monit 2008, I4:CR530-5.

32. Arends JR: Molecular interactions in the Vogelstein model of colorectal carcinoma. J Pathol 2000, 190:4I2-416.

33. Jaffe $A B$, Hall A: Rho GTPases in transformation and metastasis. Adv Cancer Res 2002, 84:57-80.

34. Bhattacharya B, Prasad GL, Valverius EM, Salomon DS, Cooper HL: Tropomyosins of human mammary epithelial cells: consistent defects of expression in mammary carcinoma cell lines. Cancer Res 1990, 50:2105-2112.

35. Wang FL, Wang Y, Wong WK, Liu Y, Addivinola F], Liang P, Chen LB, Kantoff PW, Pardee AB: Two differentially expressed genes in normal human prostate tissue and in carcinoma. Cancer Res 1996, 56:3634-3637.

36. Braverman RH, Cooper HL, Lee HS, Prasad GL: Anti-oncogenic effects of tropomyosin: isoform specificity and importance of protein coding sequences. Oncogene 1996, 13:537-545.

37. Prasad GL, Fuldner RA, Cooper HL: Expression of transduced tropomyosin I cDNA suppresses neoplastic growth of cells transformed by the ras oncogene. Proc Natl Acad Sci USA 1993, 90:7039-7043.

38. Kahl CR, Means AR: Regulation of cell cycle progression by calcium/calmodulin-dependent pathways. Endocr Rev 2003, 24:719-736.

39. Choi J, Husain M: Calmodulin-mediated cell cycle regulation: new mechanisms for old observations. Cell Cycle 2006, 5:2183-2186.

40. Kortvely E, Gulya K: Calmodulin, and various ways to regulate its activity. Life Sci 2004, 74:1065-1070.

4I. Palfi A, Kortvely E, Fekete E, Kovacs B, Varszegi S, Gulya K: Differential calmodulin gene expression in the rodent brain. Life Sci 2002, 70:2829-2855.

42. Toutenhoofd SL, Strehler EE: The calmodulin multigene family as a unique case of genetic redundancy: multiple levels of regulation to provide spatial and temporal control of calmodulin pools? Cell Calcium 2000, 28:83-96.

\section{Pre-publication history}

The pre-publication history for this paper can be accessed here:

http://www.biomedcentral.com/1471-2407/9/282/pre pub
Publish with Bio Med Central and every scientist can read your work free of charge

"BioMed Central will be the most significant development for disseminating the results of biomedical research in our lifetime. "

Sir Paul Nurse, Cancer Research UK

Your research papers will be:

- available free of charge to the entire biomedical community

- peer reviewed and published immediately upon acceptance

- cited in PubMed and archived on PubMed Central

- yours - you keep the copyright

Submit your manuscript here:

http://www.biomedcentral.com/info/publishing_adv.asp
BiolMedcentral 